\title{
A GENETIC STUDY OF HYPERTENSION IN OKAMOTO-AOKI SPONTANEOUSLY HYPERTENSIVE RATS
}

\author{
TERENCE T. YEN*, PAO-LO YU†, HAROLD ROEDER $\ddagger$ and PAUL W. WILLARD $\S$ \\ The Lilly Research Laboratories and Departemnt of Medical Genetics, \\ Indiana University School of Medicine, Indianapolis, Indiana
}

Received 22.i.74

\begin{abstract}
SUMMARY
Data from crosses between Wistar/Furth rats and spontaneously hypertensive rats indicate that there are a small number of genes ( 3 to 4$)$ controlling the hypertension trait in the Okamoto-Aoki spontaneously hypertensive rats. However, $F_{1}$ rats bred from reciprocal crosses of Sprague-Dawley rats and spontaneously hypertensive rats were hypertensive. $F_{2}$ rats bred from these $F_{1} \times F_{1}$ rats showed a 3 to 1 segregation ratio of hypertensive to normotensive rats. Furthermore, male progeny from Sprague-Dawley $\times F_{1}$ backcross segregated into a 1:1 ratio of hypertensive to normotensive rats. These data suggest that among those 3 to 4 genes that control hypertension in the spontaneously hypertensive rats there is at least one major gene. This locus is not sex-linked but its expression is modified by sex differences.
\end{abstract}

\section{INTRODUGTION}

A ROLE of heredity in the development of essential hypertension in man was first suggested by Wilhelm Weitz in 1923 (Bauer, 1968) and subsequently documented by other investigators (Bauer, 1968; McKusick, 1960). The mode of inheritance of this syndrome, however, is not yet clear. Hamilton et al. (1954) concluded from their studies that blood pressure is a multifactorial trait. Pickering (1961) subsequently maintained that blood pressure is a continuous trait and hypertension is merely the upper end. In contrast, Platt (1959) proposed that the pattern of inheritance may be a result of the action of a single gene with incomplete dominance for essential hypertension. Platt's hypothesis is supported by the studies of Morrison and Morris (1959) and by those of McDonough, Garrison and Hames (1964).

The influence of hereditary factors on the development of essential hypertension in laboratory animals has been summarised by Schlager (1972). In mice, rats, chickens and rabbits the estimate of heritability for the variation in blood pressure is about 20 per cent and the involvement of more than one gene is indicated. Among these species, the Okamoto-Aoki spontaneo usly hypertensive rats (SHR) are unique in that the incidence of hypertension is 100 per cent (Okamoto and Aoki, 1963). Substantial progress has been made in recent years on the study of these rats (Okamoto, 1972). However, the genetics of these rats is not well understood. During the course of this

* Lilly Research Laboratories, Indianapolis, Indiana 46206.

$\dagger$ Department of Medical Genetics, Indiana University School of Medicine, Indianapolis, Indiana 46207.

$\ddagger$ Deceased.

$\S$ Present address: Medical Products Division, 3M Company, St Paul, Minnesota 55101.

$33 / 3-\mathrm{U}$ 
study, reports of two independent studies on the genetics of SHR have appeared (Louis, Tabei, Sjoerdsma and Spector, 1969; Tanase, Suzuki, Ooshima, Yamori and Okamoto, 1970, 1972). In both studies, only Wistar rats, inbred or non-inbred, were used as normotensive rats to mate with SHR. In our study, both inbred Wistar/Furth rats (WFR) and noninbred Sprague-Dawley rats (SDR) were crossed to SHR. Results of both series of experiments are compared in this report.

\section{Material and methods}

Eleven Okamoto-Aoki SHR were kindly supplied by Professor K. Aoki of Nagoya City University, Nagoya, Japan. These rats belonged to the 16th generation of his inbred colony. Two male and two female siblings of these 11 SHR were bred to produce all the first-generation SHR in the Lilly colony. The blood pressure of these four rats was monitored from 25 to 70 weeks of age. That of the two female SHR varied from 168 to $199 \mathrm{~mm} \mathrm{Hg}$ and the two male SHR, 182 to $196 \mathrm{~mm} \mathrm{Hg}$. Inbred WFR were purchased from Microbiological Associates, Walkersville, Maryland. SDR were supplied by Southern Animal Farms, Prattville, Alabama. Purina Laboratory Chow and water were available ad libitum. The room was lighted with fluorescent lights from 6 a.m. to 6 p.m. daily.

Systolic blood pressure was measured by the modified method of Friedman and Freed (1949). The validity of this method in measuring the systolic blood pressure of SHR has been reported (Pfeffer, Pfeffer and Frohlich, 1971). The whole animal was warmed for 30 to 45 seconds with a microwave oven set at $32^{\circ} \mathrm{C}$. to assure audibility of the systolic pressure in the tail of each rat. The animal was restrained in a Lucite holder after being removed from the microwave oven. The systolic sound was picked up distal to an occlusion cuff, 1 inch in diameter, with a crobon microphone element and was amplified with a high gain audio-amplifier. The blood flow in the tail was occluded by a small membrane cuff that was attached to a sphygmomanometer. An average of three determinations was taken as the systolic blood pressure. All blood pressure data in this report are expressed as mean \pm s.d. in terms of $\mathrm{mm} \mathrm{Hg}$.

\section{REsults}

(i) Crosses between Wistar/Furth and spontaneously hypertensive rats

The blood pressure of our third-generation SHR, WFR, $F_{1}$ (WFR $\times$ SHR) and $F_{2}\left(F_{1} \times F_{1}\right)$ rats is shown in table 1 . The relationship of their blood pressure can be illustrated in the following mathematical form:

1. Male SHR $>$ female SHR.

2. Male $W F R=$ female $W F R$.

3. $\mathrm{F}_{1}<(\mathrm{WFR}+\mathrm{SHR}) / 2$. (Male, $\mathrm{P}<0.05$; female, $\mathrm{P}<0.01$.)

4. $\mathrm{F}_{2}>\mathrm{F}_{1}$. (Male and female, $\mathrm{P}<0.01$.)

5. Male $\mathrm{F}_{2}=$ (male WFR + male SHR) $/ 2$.

6. Female $\mathrm{F}_{2}>($ female WFR + female SHR $) / 2 . \quad(\mathrm{P}<0 \cdot 05$. $)$

The distribution of blood pressure of these four types of rats is presented in fig. 1. The blood pressure of $F_{2}$ rats had a wider spread than that of $F_{1}$ rats $(\mathrm{P}<0.01$ for males and $\mathrm{P}<0.05$ for females). 
TABLE 1

Mean blood pressure ( $\mathrm{mm} \mathrm{Hg}$ ) of Wistar/Furth rats (WFR), spontaneously hypertensive rats $(S H R)$ and rats derived from their matings

\begin{tabular}{|c|c|c|c|c|c|}
\hline & \multirow{2}{*}{$\begin{array}{c}\text { Age } \\
\text { (weeks) }\end{array}$} & \multicolumn{2}{|r|}{ Male } & \multicolumn{2}{|r|}{ Female } \\
\hline & & $\mathbf{N}$ & $\ddot{X}_{ \pm \text {s.d. }}$ & $\mathbf{N}$ & $\bar{X} \pm$ s.d. \\
\hline & 14-15 & 49 & $142 \cdot 5 \pm 6 \cdot 6$ & 50 & $143 \cdot 7 \pm 4$ \\
\hline 10 & $\begin{array}{r}17-20 \\
18\end{array}$ & $\begin{array}{l}29 \\
38\end{array}$ & $\begin{array}{l}196 \cdot 3 \pm 13 \cdot 0 \\
165 \cdot 1+6 \cdot 2\end{array}$ & 15 & $176 \cdot 1 \pm 7$ \\
\hline$F_{3}\left(F_{1} \times F_{1}\right)$ & $\begin{array}{r}18 \\
17-18\end{array}$ & 72 & $\begin{array}{l}65 \cdot 1 \pm 0.2 \\
171 \cdot 0 \pm 11.6\end{array}$ & 61 & $163.4 \pm 10 \cdot 2$ \\
\hline
\end{tabular}

* Third-generation SHR of the Lilly colony.

MALE

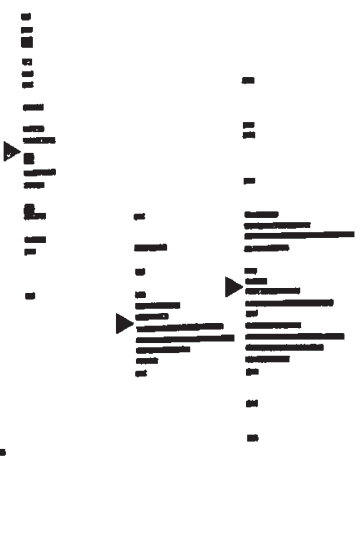

FEMALE

$\begin{array}{llll}W & \text { SH } & F_{1} & F_{2}\end{array}$

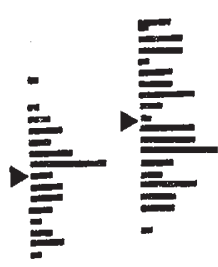

$=$

FIG. 1.-Distribution of mean blood pressure of Wistar/Furth (W) and spontaneously hypertensive $(\mathrm{SH})$ rats and rats derived from their matings. $\mathrm{F}_{1}$ rats were from female Wistar/ Furth $\times$ male $\mathrm{SH}$ and $\mathrm{F}_{2}$ rats were from $\mathrm{F}_{1} \times \mathrm{F}_{1}$. The length of the horizontal bars represents the number of rats with the shortest length equivalent to one rat. The triangle on the left of each column indicates the mean blood pressure of that group of rats. The number of rats per type is the same as that shown in table 1 .

TABLE 2

Mean blood pressure ( $\mathrm{mm} \mathrm{Hg}$ ) of Sprague-Dawley rats (SDR), spontaneously hypertensive rats $(S H R)$ and rats derived from their matings

\begin{tabular}{|c|c|c|c|c|c|}
\hline & \multirow{2}{*}{$\begin{array}{c}\text { Age } \\
\text { (weeks) }\end{array}$} & \multicolumn{2}{|r|}{ Male } & \multicolumn{2}{|r|}{ Female } \\
\hline & & $\mathbf{N}$ & $\bar{X} \pm$ s.d. & $\mathbf{N}$ & $\not{X} \pm$ s.d. \\
\hline SDR & 16 & 50 & $146 \cdot 7 \pm 6 \cdot 9$ & 50 & $136 \cdot 9 \pm 7 \cdot 3$ \\
\hline SHR* & $17-21$ & 22 & $184 \cdot 0 \pm 10 \cdot 1$ & 18 & $178 \cdot 7 \pm 11 \cdot 3$ \\
\hline $\mathrm{F}_{1} \dagger(\mathrm{SDR} \times \mathrm{SHR})$ & $18-19$ & 64 & $177 \cdot 6 \pm 7 \cdot 2$ & 67 & $166.9 \pm 8.2$ \\
\hline $\mathrm{F}_{2}\left(\mathrm{~F}_{1} \times \mathrm{F}_{1}\right)$ & $16-18$ & 44 & $172 \cdot 0 \pm 10 \cdot 6$ & 54 & $157 \cdot 0 \pm 9.5$ \\
\hline $\mathrm{BC}\left(\mathrm{SDR} \times \mathrm{F}_{1}\right)$ & $15-16$ & 19 & $161 \cdot 0 \pm 16 \cdot 5$ & 32 & $143 \cdot 4 \pm 10 \cdot 4$ \\
\hline
\end{tabular}

* First-generation SHR of the Lilly colony.

$\uparrow$ The blood pressure of $F_{1}$ rats from $S D R \times$ SHR was not significantly different from that of $F_{1}$ rats from $S H R \times S D R$. Therefore, the data on $F_{1}$ rats in this table are pooled from reciprocal crosses. 
(ii) Crosses between Sprague-Dawley and spontaneously hypertensive rats

The blood pressure of our first-generation SHR (table 2) was lower than that of our third-generation SHR (table 1). The rise of the blood pressure of the third-generation SHR could be due to the stabilisation of the environment. Reciprocal crosses were done between SHR and SDR. The blood pressure of $F_{1}$ rats from $S H R \times S D R$ was not different from that of $F_{1}$ rats from $S D R \times S H R$. Thus, the mean blood pressure of all $F_{1}$ rats is shown in table 2. The relationship of blood pressure of five types of rats shown in table 2 can be illustrated in the following mathematical form:

1. Male SHR $>$ female SHR.

2. Male SDR $>$ female SDR.

3. $\mathrm{F}_{1}>(\mathrm{SDR}+\mathrm{SHR}) / 2$. (Male and female, $\mathrm{P}<0.01$.)

4. $\mathrm{F}_{1}>\mathrm{F}_{2}$. (Male and female, $\mathrm{P}<0.01$.)

5. $\mathrm{F}_{2}=(\mathrm{SDR}+\mathrm{SHR}) / 2$.

6. Male $\mathrm{BC}=\left(\right.$ male $\mathrm{F}_{1}+$ male $\left.\mathrm{SDR}\right) / 2$.

7. Female $\mathrm{BC}<\left(\right.$ female $\mathrm{F}_{1}+$ female $\left.\mathrm{SDR}\right) / 2 . \quad(\mathrm{P}<0.01$. $)$

The distribution of the blood pressure of these various types of rats is shown in fig. $2 \mathrm{~A}$ and $\mathrm{B}$. Both male $\mathrm{F}_{2}$ rats and rats from (SDR $\times \mathrm{F}_{1}$ ) backcrosses had a wide distribution of blood pressure ranging from normotension to hypertension.

In order to classify $\mathrm{F}_{2}$ rats into normo- and hypertensive, a discriminant function was obtained for SDR and hypertensive rats. In this case, the hypertensive rats were composed of both SHR and $F_{1}$ rats. Since the blood pressure of SHR and that of $F_{1}$ rats overlap extensively (fig. $2 \mathrm{~A}$ and $\mathrm{B}$ ), it is difficult to keep $F_{1}$ rats in a separate category. The discriminant function is:

$$
z=17.5333-0.9948 X_{1}-0.1015 X_{2},
$$

where $X_{1}=\operatorname{sex}\left(X_{1}=1\right.$ for males and $X_{1}=2$ for females $)$; and $X_{2}=$ blood pressure at 16-21 weeks of age.

For each rat, a discriminant score was thus computed. The distribution of discriminant scores for normal rats and hypertensive rats (both SHR and $F_{1}$ rats) is given in fig. 3. The cut-off point for classifying $F_{2}$ rats into normal or hypertensive is set at 0.228 , which establishes the probability for misclassification in either direction at 0.023 . From our results, four of the $100 \mathrm{SDR}$ would be classified as hypertensive and two of $171 \mathrm{SHR}$ and $F_{1}$ rats would be classified as normotensive. Thus, only six out of a total of 271 rats would be misclassified. It should be noted that at $z=0 \cdot 228, X_{2}$ (blood pressure) $=160.7$ for males and 150.9 for females (equation (1)).

Based on the discriminant function given in (1), a discriminant score (Z) was computed for each $F_{2}$ rat. The rat was classified as hypertensive if its discriminant score was less than or equal to $0 \cdot 228$; otherwise, it was classified as normotensive. The results of classification are given in table 3. In fitting the number of hypertensive rats and that of normotensive rats to a 2 to 1 ratio, a $\chi^{2}$ value of 0.217 is obtained with Yate's correction. The probability level for this $\chi^{2}$ is between 0.6 to 0.7 . 
(A)
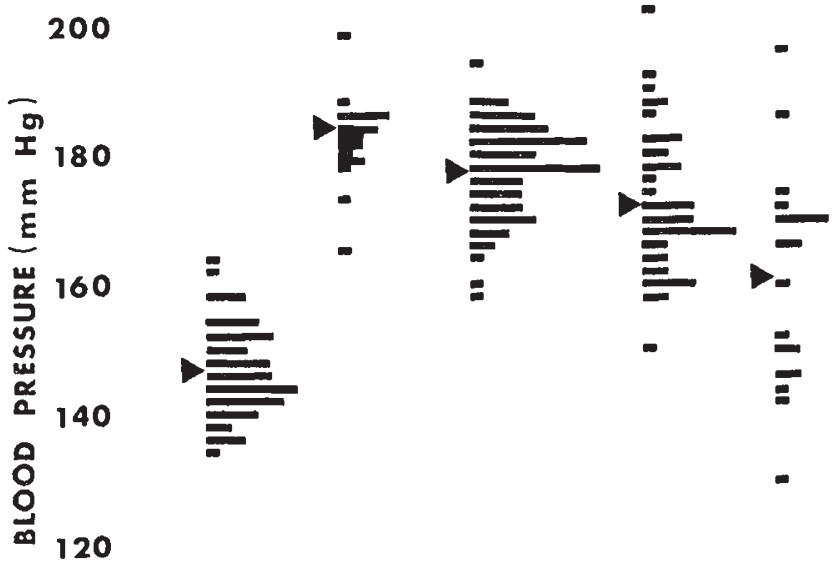

SD

$$
\text { SH }
$$

$$
\mathbf{F}_{\mathbf{1}}
$$

$F_{2} \quad \mathbf{B C}$

220

(B)

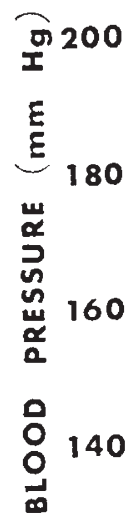

120

$$
\text { ) }
$$<smiles>C1CCCC1</smiles> 


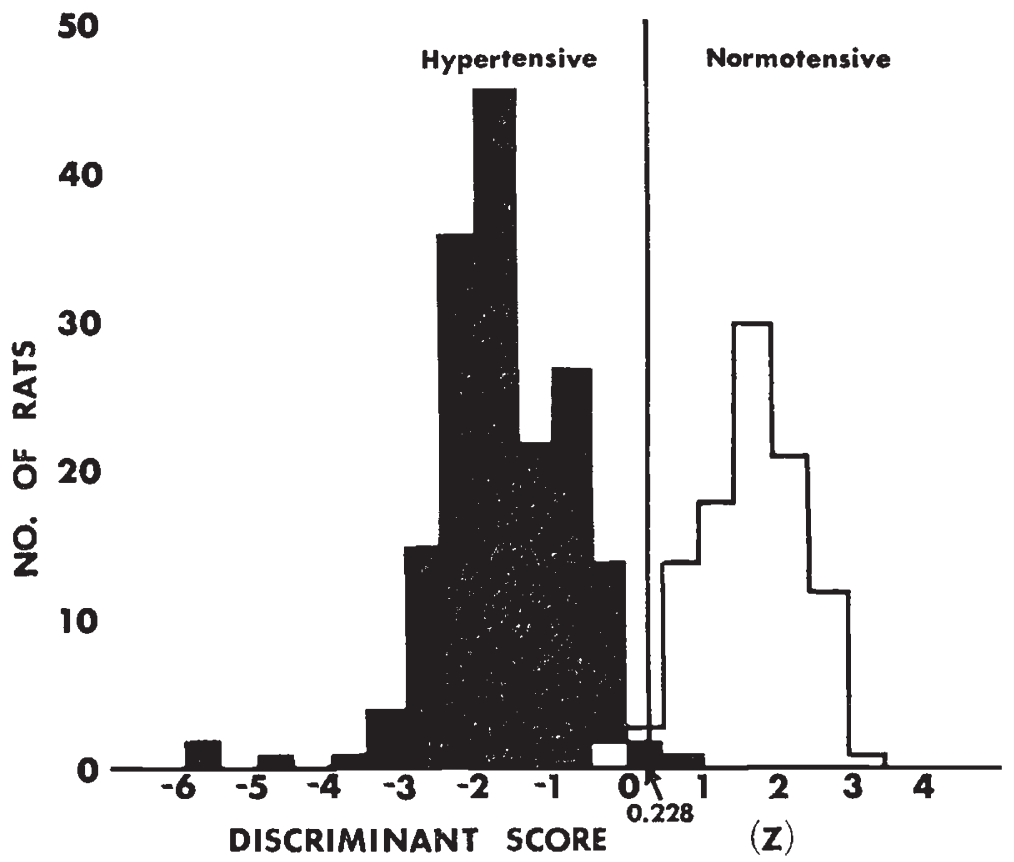

FIG. 3.-The distribution of discriminant scores for normal rats and hypertensive rats (both SHR and $F_{1}$ rats from reciprocal crosses of SDR $\times$ SHR). See text for the computation of discriminant scores. $Z=0.228$ is used to classify $F_{2}$ rats as normotensive or hypertensive to make the probability for misclassification in either direction $0 \cdot 023$.

TABLE 3

Classification of $F_{2}$ rats

$\begin{array}{lcc} & & \text { Expected No. } \\ \text { Normal } & \text { No. of } F_{2} \text { rats } & \text { for a } 3: 1 \text { ratio }\end{array}$

\section{Discussion}

Our data from crosses between WFR and SHR are compatible with those of Tanase et al. $(1970,1972)$. The blood pressure of $F_{1}$ rats was slightly lower than the average blood pressure of the parental rats (table 1 and fig. 1). The same was observed by Tanase et al. on both male and female $F_{1}$ rats from $S H R \times$ Wistar-Kyoto and on female $F_{1}$ rats from SHR $\times$ Wistar-Mishima (Tanase, 1970). Also, neither we (fig. 1) nor Tanase et al. (1970) observed any single gene segregation among the $\mathrm{F}_{2}$ rats. This suggests that there is more than one gene involved in controlling the hypertension trait in these rats. Based on the data from WFR $\times$ SHR, our estimate of number of loci according to the method of Wright (1952) indicates that there are 2.75 (from data on female rats) to 3.76 (from data on male rats) genes involved. This estimate agrees well with that made by Tanase et al. (1970).

On the other hand, crosses between SDR and SHR suggest that among 
these three to four genes, there is at least one major gene. This is indicated by the 3 to 1 segregation ratio among the $F_{2}$ rats (table 3 ). Furthermore, among the 19 backcross males, 10 could be classified as hypertensive and 9 normotensive according to their discriminant scores as calculated according to equation (1), thus fitting a 1 to 1 ratio. The classification of the backcross female into a hypertensive group and a normotensive group does not fit a 1 to 1 ratio. The reason for that is discussed in the next paragraph.

In this study, the blood pressure of all male rats was higher than that of corresponding types of female rats except for WFR. However, the blood pressure of $F_{1}$ rats from reciprocal crosses of $\mathrm{SDR} \times \mathrm{SHR}$ was not significantly different, suggesting that this major gene is not sex-linked. Also, we have not observed any maternal or paternal influence as reported by Tanase $e t$ al. $(1970,1972)$. Since bilateral gonadectomy did not affect the blood pressure of SHR (Aoki, 1963), the different balance of sex hormones, gonadotrophins and corticosteroids in males and females does not seem to account for the differential expression of this major gene in male and female rats in this particular strain. Pregnancy, however, did affect the blood pressure in the last third of the gestation period (Takeda, 1964). Applying the criterion of hypertension in this study, the onset of hypertension coincides with puberty. It thus seems reasonable to conclude that although sex hormones are not directly involved in the expression of this major gene, its expression is affected by some subtle sex difference. Such sex difference may underlie the difficulty in interpreting the blood pressure of female rats such as those of backcross females from $\mathrm{SDR} \times \mathrm{F}_{1}$ (table 2).

The observation that there is a single locus that is capable of controlling blood pressure by itself certainly does not exclude the possibility of the presence of other loci that could affect blood pressure independently or in conjunction with this locus. The existence of other genes is certainly indicated by crosses between WFR and SHR in our study and by the studies of Tanase et al. $(1970,1972)$. One analogy to this is the identification of the genes agouti, obese and diabetes in mice (Green, 1966). All of them can independently modify body weight. The possible existence of such a locus, among other genes, that controls blood pressure prompted us to isolate this gene by introducing it into the genome of the inbred Wistar/ Lewis strain. Thus far, we have been able to maintain the hypertensive trait in the progeny from the third backcross. Tanase et al. (1972) recently reported that they had undertaken a similar effort. It will be very interesting to compare the results of these two independent studies in the future.

Acknowledgments. - The authors are greatly indebted to Professor Kyuzo Aoki, M.D., Ph.D., of Nagoya City University, Nagoya, Japan, for his generous gift of 11 OkamotoAoki spontaneously hypertensive rats which made this study possible.

The work of PLY is supported in part by USPHS grants HL14159 and DE119.

The authors wish to acknowledge the use of the computer at the Research Computation Center, Indiana University Medical Center.

The support and cooperation of Drs C. Matsumoto and I. H. Slater of the Lilly Research Laboratories is also appreciated.

\section{REFERENGES}

AOKI, K. 1963. Experimental studies on the relationship between the endocrine organs and hypertension in spontaneously hypertensive rats. 1. Effects of hypophysectomy, adrenalectomy, thyroidectomy, nephrectomy and sympathectomy on blood pressure. Fap. Heart f., 4, 443-461. 
BAUER, J. 1968. Genetics of essential hypertension. Acta Geneticae Medicae et Gemellologiae, $18,577-583$

FRIEDMAN, M., AND FREED, s. c. 1949. Microphonic manometer for indirect determination of systolic blood pressure in the rat. Proc. Soc. Exptl. Biol. Med., 70, 670-672.

GREEN, E. L. 1966. The Biology of the Laboratory Mouse. McGraw-Hill, New York.

HAMILTON, M. G., PICKERING, G. W., ROBERTS, J. A. F., AND sOWRY, G. S. c. 1954. The etiology of essential hypertension. 4. The role of inheritance. Clin. Sci., 13, 273-304.

LOUIS, W. J., TABEI, R., SJOERDSMA, A., AND SPECTOR, s. 1969. Inheritance of high blood pressure in the spontaneously hypertensive rat. Lancet, 1, 1035-1036.

MCDONOUGH, J. R., GARRISON, G. E., AND HAMES, G. C. 1964. Blood pressure and hypertensive disease among negroes and whites. A study in Evans County, Georgia. Ann. Int. Med., 61, 208-228.

MCKusicK, v. A. 1960. Genetics and the nature of essential hypertension. Circulation, 22, 857-863.

MORRISON, S. L., AND MORRIS, J. N. 1959. Epidemiological observations on higher blood pressure without evident cause. Lancet, 2, 864-870.

охамото, к. 1972. Spontaneous Hypertension, Its Pathogenesis and Complications. SpringerVerlag, Berlin.

окамото, K., AND AOKI, K. 1963. Development of a strain of spontaneously hypertensive rats. Fap. Circulation F., 27, 282-293.

PFEFFER, J. M., PFEFFER, M. A., AND FROHLICH, E. D. 1971. Validity of an indirect tail-cuff method for determining systolic arterial pressure in unaesthetized normotensive and spontaneously hypertensive rats. F. Lab. Clin. Med., 78, 957-962.

Pickering, G. w. 1961. The Nature of Essential Hypertension. J. and A. Churchill, Ltd., London.

PLATT, R. 1959. The nature of essential hypertension. Lancet, 2, 55-59.

SCHLAGER, G. 1972. Spontaneous hypertension in laboratory animals. F. Heredity, 63, 35-38.

TAKRDA, T. 1964. Experimental study on the blood pressure of pregnant hypertensive rats. 1. Effect of pregnancy on the course of experimentally and spontaneously hypertensive rats. Fap. Circulation F., 28, 49-54.

TANASE, H., SUZUKI, Y., OOSHIMA, A., YAMORI, Y., AND OKAMOTO, K. 1970. Genetic analysis of blood pressure in spontaneously hypertensive rats. Fap. Circulation F., 34, 1197-1212.

TANASE, H., SUZUKI, Y., OOSHIMA, A., YAMORI, Y., AND OKAMOTO, K. 1972. Further genetic analysis of blood pressure in spontaneously hypertensive rats. In Spontaneous Hypertension, K. Okamoto, ed. Igaku Shoin Ltd., Tokyo.

WRIGHT, s. 1952. The genetics of quantitative variability. In Quantitative Genetics, E. C. R. Reive and C. H. Waddington, eds. H.M.S.O., London. 